\title{
JURNAL PHENOMENON
}

phenomenon@walisongo.ac.id

\section{SIMPLE CHATBOT DEVELOPMENT TO HELP STUDENTS UNDERSTANDING EDUCATIONAL RESEARCH METHODOLOGY}

\author{
Muhammad Izzatul Faqih ${ }^{1}$, Mustofa ${ }^{2}$ \\ ${ }^{1,2}$ UIN Walisongo Semarang
}

\begin{abstract}
Abstrak
Penelitian ini bertujuan untuk (1) Mengembangkan chatbot sederhana untuk membantu mahasiswa memahami metodologi penelitian pendidikan, (2) Mengetahui kelayakan chatbot sederhana untuk membantu mahasiswa memahami metodologi penelitian pendidikan, (3) Mengetahui respon chatbot sederhana untuk membantu mahasiswa memahami metodologi penelitian pendidikan. Jenis penelitian ini adalah penelitian Research and Developement (RND). Teknik pengumpulan data menggunakan observasi, angket, dan dokumentasi. Hasil penelitian aplikasi tersebut layak digunakan yaitu ditandai dengan skor 4,425 yang diberikan oleh 4 ahli teknologi. Pada penilaian SUS aplikasi secara adjective rating bernilai excellent, dengan grade scale bekategori B dan acceptability ranges masuk pada acceptable
\end{abstract}

Kata kunci: chatbot, metodologi penelitian pendidikan

\section{PENDAHULUAN}

Penguasaan tentang metodologi penelitian pendidikan memegang peranan penting dalam menentukan kemampuan mahasiswa menyelesaikan tugas akhir skripsi (TAS). Dengan pemahaman yang baik tentang metodologi maka mereka dapat menemukan masalah dengan mudah dalam melakukan penelitian. Jika masalah mudah didapatkan dan metodologi dikuasai dengan baik maka TAS akan diselesaikan dengan singkat.

Permasalahan yang timbul pada mahasiswa ketika sudah mengambil TAS adalah menentukan judul penelitian dan metode yang akan digunakan. Secara umum jika mahasiswa menguasai metodologi penelitian maka akan sangat mudah juga dalam menetukan judul yang akan diambil.

Kenyataan tidak se-ideal yang dibayangkan, mahasiswa akhir masih tetep sulit untuk lulus tepat waktu karena masih terkendala dalam memilih judul penelitian. Salah 
satu hal yang menyebabkan mereka kesulitan memilih judul sesuai hasil observasi peneliti adalah karena mereka tidak memahami metodologi penelitian. Rerata nilai yang sangat memuaskan pada matakuliah metodologi penelitian yang diambil sebelumnya ternyata tidak cukup menggambarkan kemampuan mereka dalam mengaplikasikan metodologi penelitian.

Nilai yang sangat memuaskan ternyata tidak menggambarkan pemahaman komprehensif mengenai kemampuan mahasiswa untuk melakukan penelitian. Hal itu dapat dilihat seperti yang sudah dijelaskan sebelumnya bahwa banyak mahasiswa yang tidak lulus tepat waktu karena sulit menentukan judul skripsi.

Oleh karena itu, peneliti akan mengembangkan sebuah sistem yang akan membantu mahasiswa pendidikan untuk memahami metodologi penelitian secara komprehensif melalui sebuah aplikasi chatbot. Sesuai dengan Shawar \& Atwell, 2007 (dalam Ross, S.: 2018) menyatakan bahwa chatbot dapat digunakan sebagai alat pencarian informasi dan untuk menjawab pengguna tentang topik tertentu. Lebih lanjut Ross menyatakan bahwa chatbots masih belum banyak digunakan dalam dunia pendidikan.

Winkler, R. \& Söllner, M. (2018) chatbots adalah program komputer yang digunakan untuk melakukan percakapan tekstual atau suara. Semakin banyak bukti menunjukkan bahwa program-program ini memiliki potensi untuk mengubah cara mahasiswa belajar dan mencari informasi. Terutama dalam pembelajaran dengan jumlah mahasiswa lebih dari 100 untuk tiap dosen. Chatbots dapat menyelesaikan masalah dukungan siswa secara individu. Namun begitu masih belum ada ikhtisar sistematis dan terstruktur pada penggunaanya dalam pendidikan.

Diharapkan dengan adanya aplikasi ini pemahaman dan penerapan mahasiswa tentang metodologi penelitian pendidikan akan meningkat. Implikasinya mereka akan dengan mudah menentukan judul penelitian dan akan semakin banyak mahasiswa yang lulus tepat waktu.

\section{METODE PENELITIAN}

Prosedur yang digunakan untuk menggali data adalah Research and Developement (R\&D) oleh Borg and Gall (1983:775). Berdasarkan sepuluh langkah pelaksanaan strategi penelitian dan pengembangan yang dilakukan oleh Borg dan Gall, maka penelitian ini menggunakan langkah pertama sampai langkah kelima, yakni penelitian 
dan pengumpulan informasi, perencanaan, pengembangan draf produk, uji coba dan merevisi hasil ujicoba.

Dengan mengacu pada lima langkah yang diambil, alur prosedur penelitian secara ringkas dapat dilihat pada gambar 1 berikut:

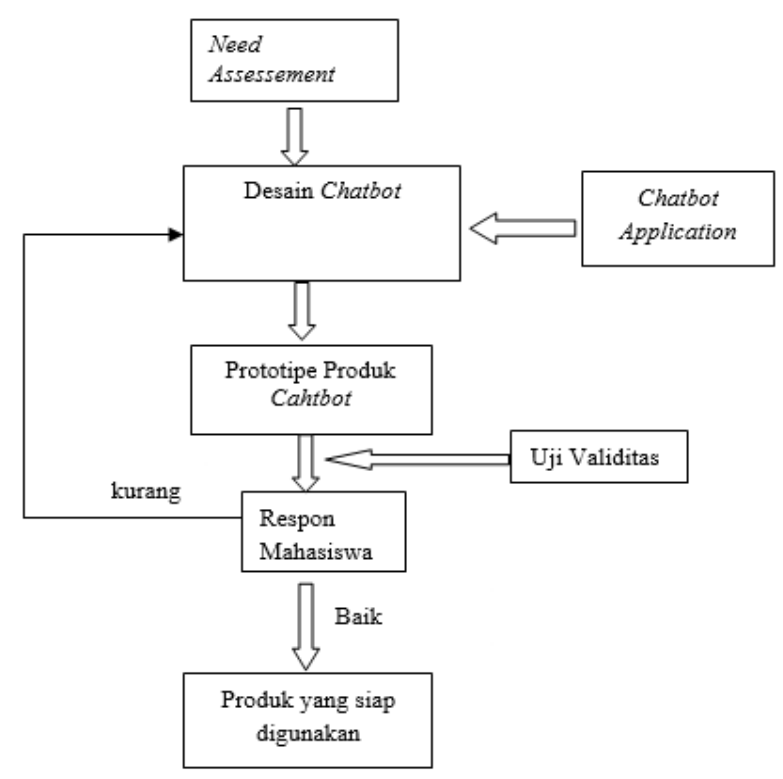

\section{Gambar 1. Prosedur Pelaksanaan Penelitian}

Hasil dari chatbot yang telah dibuat maka akan diuji validitasnya oleh pakar. Setelah uji pakar terpenuhi kriterianya, maka selanjutnya akan digunakan secara praktis pada mahasiswa. Pengujian praktis digunakan untuk konsultasi melalui chatbot pada mahasiswa. Setelah digunakan dalam konsultasi mahasiswa mengisi respon yang untuk perbaikan dari chatbot yang telah dibuat. Hasil dari prototipe produk chatbot yang telah teruji validitasnya, apabila kurang maka perlu perbaikan lagi namun jika sudah baik dapat diterapkan.

\section{HASIL DAN PEMBAHASAN}

Hasil dari penelitian dan pembahasan akan dipaparkan tentang bagaimana produk dikembangkan sampai dengan produk terakhir dibuat beserta keterbatasannya. Secara lebih detail. Pengembangan ini bertujuan untuk menciptakan produk berupa aplikasi android untuk membantu mahasiswa memahami metodologi penelitian pendidikan dan mengetahui kualitasnya secara teori dari pakar teknologi. Oleh karena itu, model 
pengembangan diperlukan utnuk mencapai tujuan yang sudah ditetapkan. Model yang digunakan dalam pemngembangan adalah Borg \& Gall. Langkahnya yaitu penelitian dan pengumpulan informasi, perencanaan, pengembangan draf produk, uji coba dan merevisi hasil ujicoba.

Pertama, dengan penelitian dan pengumpulan informasi (research and information collecting). Pada tahap ini peneliti melakukan need assessement atau penilaian kebutuhan terhadap aplikasi yang akan dikembangkan. Pada saat penilaian kebutuhan didapatkan beberapa hal penting diantaranya: (1) banyaknya mahasiswa yang lulus tidak tepat waktu, (2) kesulitan mahasiswa menentukan judul penelitian, (3) nilai mahasiswa pada matakuliah metodologi penelitian yang cukup baik.

Hasil dari penilaian kebutuhan dijadikan dasar untuk menyelidiki keterkaitan antara ketiganya. Kesimpulan yang dapat diambil adalah meskipun pada matakuliah metodologi penelitian mendapat nilai yang baik dan pernah membuat sebuah proposal dalam tugas akhirnya, masih banyak mahasiswa yang kesulitan dalam menentukan judul untuk skripsi. Dengan hambatan ini maka jangka waktu studi mereka menjadi bertambah dan lulus dengan tidak tepat waktu..

Kedua, langkahnya adalah perencanaan (planning). Perencanaan dilakukan untuk mengatasi masalah. Solusi yang ditaawarkan berupa pengembangan aplikasi chatbot. Aplikasi ini dirancang untuk berjalan di sistem operasi android dan berguna untuk membantu mahasiswa memahami kembali metodologi penelitian pendidikan dengan bantuan smartfone yang mereka miliki. Chatbot ini akan menjadi asisten mereka untuk memahami metodologi penelitian dan memudahkan dalam menentukan judul penelitian beserta metodologi dan analisis yang digunakan.

Rancangan awal aplikasi memerlukan persiapan. Hal yang perlu dipersiapkan berupa Integrated Development Environtment (IDE) berupa android studio, koneksi firebase dan dialogflow. Bahasa pemrograman yang digunakan dalam pembuatan aplikasi ini adalah kotlin. Yang dikembangkan oleh JetBrains. Setelah semua disiapkan maka pengembangan aplikasi chatbot dapat dilakukan. Penjelasan selengkapnya dapat dilihat pada pemaparan berikut.

Alur rancangan aplikasi yang akan dibuat dapat dilihat pada gambar 2. Aplikasi chatbot dikembangkan berdasarkan alur yang sederhana dimulai dengan masukan yang diberikan user pada aplikasi lalu diteruskan kedalam databases berupa firebase lalu 
diolah dengan menggunakan dialogflow.

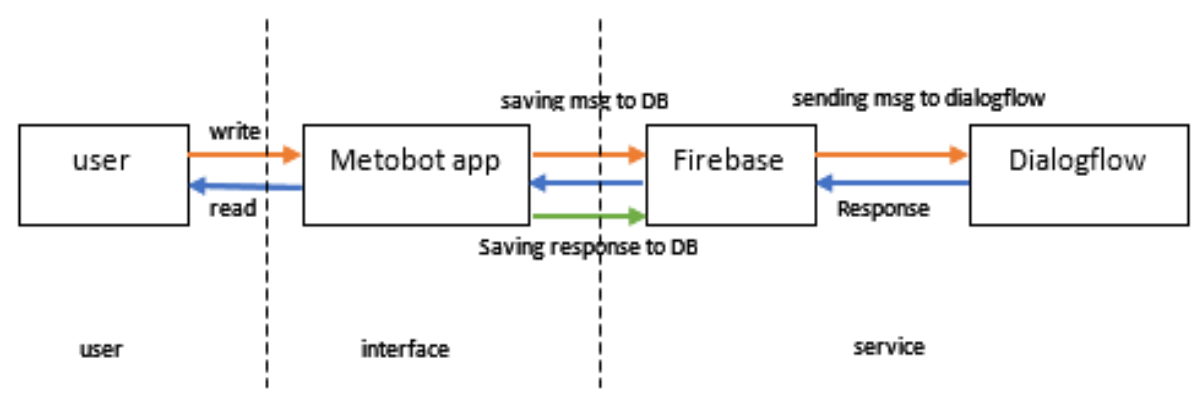

Gambar 2. Alur Rancangan Perangkat Lunak

Aplikasi atau program akan berjalan pada test device dengan baik jika terinstal di smartfone seperti pada gambar 3 yaitu terdapat shortcut yang bisa diklik untuk membuka aplikasi yang sudah dibuat.

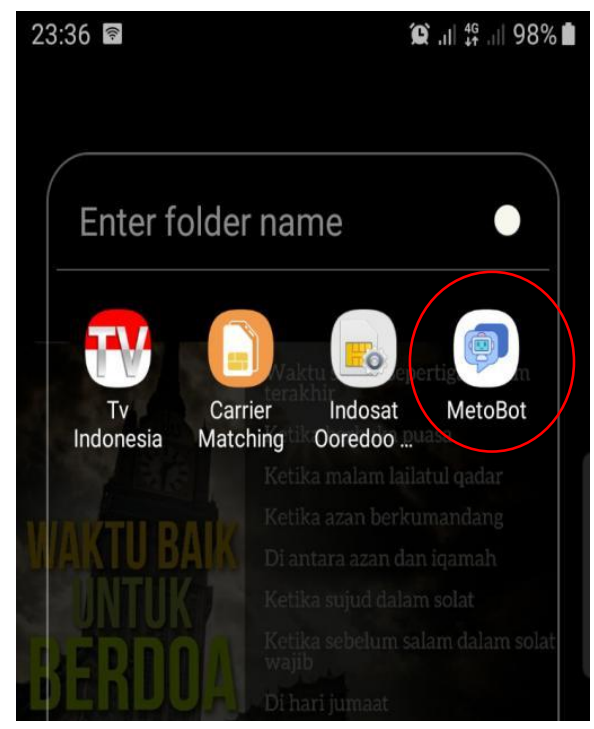

\section{Gambar 3. Tampilan Aplikasi Pada Smartfone}

Setelah diklik dan aplikasi terbuka maka akan muncul pop up berupa penjelasan singkat tentang aplikasi yang dibuat. Penjelasan tertampil seperti gambar 4 . 


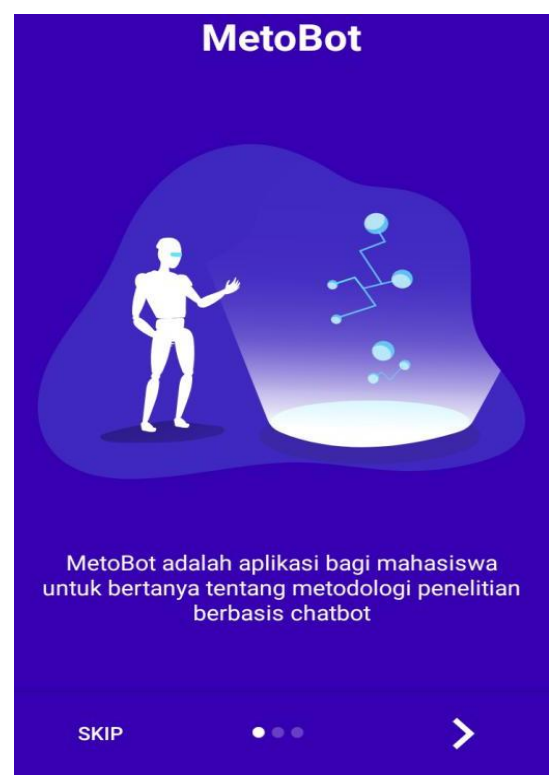

\section{Gambar 4. Slider Intro}

Ketika tombol skip diklik maka akan ada user interface yang merupakan tampilan utama aplikasi. Pada tampilan tersebut akan dijelaskan mengenai apa itu aplilasi chatbot. Hasil dari aplikasi mobile yang dibuat dalam bentuk "apk".

Validasi aplikasi mobile dilakukan pada 4 ahli teknologi. Keputusan apakah aplikasi dapat digunakan secara langsung, dengan revisi atau tidak dapat digunakan adalah pada tahap ini. Beberapa saran untuk memperbaiki aplikasi diantaranya adalah:

1. Aplikasi yang hanya terdapat prototipe database penelitian eksperimen ditambah dengan penelitian yang lain.

2. Memperbanyak text input pada intent dialog flow

Hasil validasi dapat dilihat pada tabel 1. Dari hasil validasi yang dilakukan oleh pakar maka dapat disimpulkan bahwa aplikasi yang dibuat dapat digunakan dengan beberapa perbaikan. Nilai 4,425 menandakan jika aplikasi yang dibuat berkategori sangat baik dengan catatan perlu diperbaiki.

Tabel 1. Rerata Skor Validitas Ahli Teknologi

\begin{tabular}{llllllllllll}
\hline \multirow{2}{*}{ No. } & \multicolumn{1}{l}{ Pertanyaan } \\
\cline { 2 - 12 } & $\mathbf{1}$ & $\mathbf{2}$ & $\mathbf{3}$ & $\mathbf{4}$ & $\mathbf{5}$ & $\mathbf{6}$ & $\mathbf{7}$ & $\mathbf{8}$ & $\mathbf{9}$ & $\mathbf{1 0}$ & Jumlah \\
\hline $\mathbf{1}$ & 4 & 4 & 4 & 4 & 4 & 4 & 4 & 4 & 5 & 5 & 42 \\
\hline $\mathbf{2}$ & 5 & 4 & 3 & 5 & 5 & 4 & 4 & 5 & 5 & 5 & 45 \\
\hline $\mathbf{3}$ & 4 & 4 & 4 & 5 & 5 & 4 & 5 & 5 & 5 & 5 & 46 \\
\hline $\mathbf{4}$ & 4 & 4 & 4 & 4 & 5 & 4 & 5 & 5 & 5 & 4 & 44 \\
\hline \multicolumn{2}{l}{ Rerata } & \multicolumn{1}{l}{}
\end{tabular}


Draft hasil dari pengembangan produk awal divalidasi oleh pakar untuk mengetahui validitasnya. Hal ini penting dilakukan karena merupakan bagian dari proses pengembangan dari model Borg \& Gall. Setelah validasi produk dengan beberapa perbaikan, selanjutnya digunakan untuk mengetahui respon mahasiswa terhadap aplikasi yang ada. Repon mahasiswa tentang aplikasi dapat dilihat pada tabel 2.

Tabel 2. Rerata Respon Mahasiswa Terhadap Aplikasi

\begin{tabular}{lllllllllllll}
\hline No. & \multicolumn{1}{l}{ Pertanyaan } & & & & & & & & & & & Dikali \\
& $\mathbf{1}$ & $\mathbf{2}$ & $\mathbf{3}$ & $\mathbf{4}$ & $\mathbf{5}$ & $\mathbf{6}$ & $\mathbf{7}$ & $\mathbf{8}$ & $\mathbf{9}$ & $\mathbf{1 0}$ & Jumlah & $\mathbf{2 . 5}$ \\
\hline $\mathbf{1}$ & 4 & 3 & 5 & 2 & 4 & 2 & 5 & 2 & 4 & 5 & 36 & 90 \\
\hline $\mathbf{2}$ & 4 & 2 & 4 & 2 & 4 & 2 & 4 & 2 & 3 & 4 & 31 & 77.5 \\
\hline $\mathbf{3}$ & 3 & 4 & 4 & 4 & 3 & 4 & 3 & 4 & 4 & 5 & 38 & 95 \\
\hline $\mathbf{4}$ & 4 & 2 & 5 & 1 & 4 & 2 & 5 & 1 & 5 & 2 & 31 & 77.5 \\
\hline $\mathbf{5}$ & 5 & 4 & 4 & 3 & 5 & 2 & 4 & 3 & 5 & 3 & 38 & 95 \\
\hline $\mathbf{6}$ & 5 & 2 & 5 & 2 & 4 & 3 & 5 & 1 & 2 & 4 & 33 & 82.5 \\
\hline $\mathbf{7}$ & 4 & 2 & 4 & 1 & 3 & 2 & 5 & 2 & 4 & 4 & 31 & 77.5 \\
\hline $\mathbf{8}$ & 3 & 2 & 5 & 2 & 4 & 3 & 5 & 1 & 3 & 3 & 31 & 77.5 \\
\hline $\mathbf{9}$ & 3 & 3 & 4 & 5 & 3 & 2 & 4 & 2 & 3 & 4 & 33 & 82.5 \\
\hline $\mathbf{1 0}$ & 4 & 3 & 5 & 3 & 4 & 1 & 4 & 3 & 3 & 4 & 34 & 85 \\
\hline $\mathbf{1 1}$ & 5 & 2 & 5 & 2 & 3 & 3 & 4 & 2 & 5 & 4 & 35 & 87.5 \\
\hline $\mathbf{1 2}$ & 4 & 2 & 4 & 3 & 4 & 2 & 5 & 2 & 4 & 3 & 33 & 82.5 \\
\hline $\mathbf{1 3}$ & 5 & 3 & 5 & 1 & 3 & 2 & 5 & 1 & 5 & 2 & 32 & 80 \\
\hline $\mathbf{1 4}$ & 3 & 1 & 5 & 1 & 3 & 2 & 5 & 1 & 4 & 1 & 26 & 65 \\
\hline $\mathbf{1 5}$ & 4 & 3 & 5 & 1 & 4 & 2 & 5 & 1 & 3 & 2 & 30 & 75 \\
\hline & & & & & & & & & Jumlah & 32.80 & 82.00 \\
\hline
\end{tabular}

Sesuai dengan penilaian System Usability Scale (SUS), maka dapat disimpulkan bahwa aplikasi secara adjective rating berada pada level excellent. Jika dilihat dari grade scale maka akan masuk dalam kategori B. Sedangkan pada level acceptability ranges masuk pada acceptable.

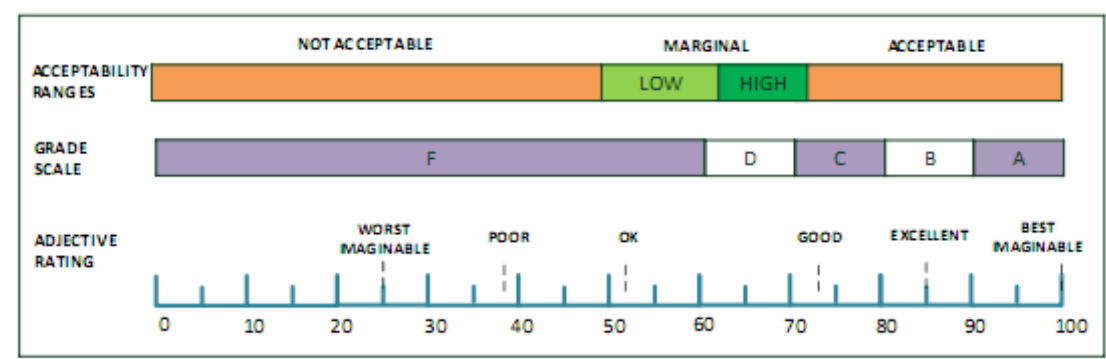




\section{Gambar 5. Skala SUS}

\section{SIMPULAN}

Berdasarkan hasil penelitian dan pengembangan dapat disimpulkan bahwa aplikasi chatbot dapat dibuat dengan baik sesuai dengan langkah pengembangan Borg \& Gall. Aplikasi tersebut layak digunakan yaitu ditandai dengan skor 4,425 yang diberikan oleh 4 ahli teknologi. Pada penilaian SUS aplikasi secara adjective rating bernilai excellent, dengan grade scale bekategori B dan acceptability ranges masuk pada acceptable.

\section{DAFTAR PUSTAKA}

Abdul-Kader, S.A. \& John Woods. 2015. Survey on Chatbot Design Techniques in Speech Conversation Systems .Journal. (IJACSA) International Journal of Advanced Computer Science and Applications, Vol. 6, No. 7, 2015

Accenture Interactive. 2016. Chatbots in Customer Service. United States of America (USA)

Anonim. 2014. Methodology of Educational Research And Statistics. Golden House, Daryaganj, New Delhi: Laxmi Publications (P) Ltd.

Anonim. 2018. Edtech Mindset Your Must-Have Educational Guide to The Future. Diakses online pada tanggal 15 Agustus 2019 melalui Mincet.org

Ary, D. et al. 2010. Introduction to Research in Education. Wadsworth: Belmont, USA

Baht, M.S. 2016. Methodology of Educational Research-I. Kashmir: Department of Education, Central University of Kashmir

Bii, P. 2013. Chatbot technology: A possible means of unlocking student potential to learn how to learn. Journal. International Research Journals, Vol.4 (2), 2013

Bii, P.K., et al. 2018. Teacher Attitude towards Use of Chatbots in Routine Teaching. Journal. Universal Journal of Educational Research 6(7): 1586-1597, 2018

Brustenga, G.G, et al. 2018. Briefing Paper Chatbots. Barcelona: UOC eLearn Center Chandana, et al. 2019. Artificial Intelligence Chatbots-An Interactive Technology. Journal. JASC: Journal of Applied Science and Computations, Volume VI, Issue I, January 2019 
Cohen, L. et al. 2007. Research Methods in Education. Madison Avenue, New York: Routledge

Colace, F., et al. 2018. Chatbot for E-Learning: A Case of Study. Journal. International Journal of Mechanical Engineering and Robotics Research Vol. 7, No. 5, September 2018

Flemin, M., et al. 2018. Streamlining Student Course Requests using Chatbots. Proceedings. AAEE2018, Hamilton, New Zealand

Gay, et al. 2012. Educational Research: Competencies for Analysis And Applications. USA: Pearson Education, Inc.

Godin, B. \& Joseph, L. A Short History of Research and Development as Categories. Published in German in Gegenworte Special Issue on Basic vs Applied Research.

Hall, B.H. 2006. Research and Develpement. Contribution to the International Encyclopedia of the Social Sciences, Second Edition.

Higher Research Commission. 2012. Methods in Education. USA Columbia University

Hiremath, G., et al. 2018. Chatbot for Education System. Journal. International Journal of Advance Research, Ideas and Innovations in Technology, Volume 4, Issue 3, 2018

Johannsen, et al. 2018. Comparison of Commercial Chatbot Solutions for Supporting Customer Interaction. Journal. Twenty-Sixth European Conference on Information Systems (ECIS2018), Portsmouth,UK, 2018

Kurniawan, A. 2018. Metodologi Penelitian Pendidikan. Bandung PT. Remaja Rosdakarya

Nursyahidah, F. Penelitian Pengembangan.

Radziwill, N. \& Morgan, B. __. Evaluating Quality of Chatbots and Intelligent Conversational Agents. Diakses Online pada tanggal 15 Agustus 2019

Ross, S. 2018. Chatbots In Education: A Passing Trend or A Valuable Pedagogical Tool?. Uppsala University: Department of Informatics and Media

Sandoval, Z.V., et al. 2018. Design and Implementation of A Chatbot in Online Higher Education Settings. Journal. Issues in Information Systems, Volume 19, Issue 4, pp. $44-52,2018$ 
Shukla, V.K \& Verma, A. . Enhancing LMS Experience through AIML Base and Retrieval Base Chatbot using R Language. Dubai, UEA: Department of Humanities Arts and Applied sciences, Amity University

Tiwari, A., et al. 2017. College Information Chat Bot System. Journal. International Journal of Engineering Research and General Science Volume 5, Issue 2, March-April, 2017

Winkler, R. \& Söllner, M. (2018): Unleashing the Potential of Chatbots in Education: A State-Of-The-Art Analysis. In: Academy of Management Annual Meeting (AOM). Chicago, USA. 